\title{
In vitro and in vivo inhibition of human Fanconi anemia head and neck squamous carcinoma by a phytonutrient combination
}

\author{
M.W. ROOMI, T. KALINOVSKY, N.W. ROOMI, A. NIEDZWIECKI and M.RATH \\ Dr Rath Research Institute, Santa Clara, CA 95050, USA
}

Received December 8, 2014; Accepted January 29, 2015

DOI: $10.3892 / \mathrm{ijo} .2015 .2895$

\begin{abstract}
Head and neck squamous cell carcinoma (HNSCC) and acute myeloid leukemia are the major causes of mortality and morbidity in Fanconi anemia (FA) patients. The objective of this study was to investigate the antineoplastic activity of $\mathrm{PB}$, an antineoplastic nutrient mixture (containing quercetin, curcumin, green tea, cruciferex and resveratrol) on human FA HNSCC in vitro and in vivo. Human FA HNSCC cell line OHSU-974 (Fanconi Anemia Research Fund) was cultured in RPMI medium supplemented with $20 \%$ FBS and antibiotics. At near confluence, cells were treated in triplicate with different concentrations of PB: 0, 10, 25, 50, 75 and $100 \mu \mathrm{g} / \mathrm{ml}$. Cells were also treated with PMA to induce MMP-9 activity. Cell proliferation was detected by MTT assay, secretion of MMPs by gelatinase zymography, invasion through Matrigel, migration by scratch test and morphology by hematoxylin and eosin (H\&E) staining. In vivo, athymic male nude mice $(n=12)$ were inoculated with $3 \times 10^{6}$ OHSU-974 cells subcutaneously and randomly divided into two groups: group A was fed a regular diet and group B a regular diet supplemented with $1 \%$ PB. Four weeks later, the mice were sacrificed and their tumors were excised, weighed and processed for histology. NM inhibited the growth of OHSU-974 tumor by $67.6 \%(\mathrm{p}<0.0001)$ and tumor burden by $63.6 \%(\mathrm{p}<0.0001)$. PB demonstrated dose-dependent inhibition of cell proliferation, with $27 \%(\mathrm{p}=0.0003)$ and $48 \%(\mathrm{p}=0.0004)$ toxicity at 75 and $100 \mu \mathrm{g} / \mathrm{ml}$, respectively. Zymography revealed MMP-2 and PMA-induced MMP-9 secretion. PB suppressed secretion of both MMPs in a dose-dependent manner, with total block of both at $50 \mu \mathrm{g} / \mathrm{ml}$. PB inhibited cell migration (by scratch test) and OHSU-974 invasion through Matrigel in a dose-dependent fashion with total block at $50 \mu \mathrm{g} / \mathrm{ml}$. H\&E staining showed no morphological changes below $50 \mu \mathrm{g} / \mathrm{ml}$. The results suggest
\end{abstract}

Correspondence to: Dr Aleksandra Niedzwiecki, Dr Rath Research Institute, 1260 Memorex Drive, Santa Clara, CA 95050, USA E-mail: author@drrath.com

Key words: Fanconi anemia, head and neck squamous carcinoma, phytonutrients, tumor growth, MMPs, Matrigel invasion, cell migration that PB has potential therapeutic use in the treatment of human FA HNSCC.

\section{Introduction}

Head and neck squamous cell carcinomas (HNSCC), known for their aggressive growth and propensity to metastasize, are among the most common tumors developed in patients with Fanconi anemia (1,2). Although morphologically the cancer is the same, the incidence and course of HNSCC is altered in FA patients. Incidence of HNSCC reaches $14 \%$ among Fanconi anemia patients by age 40 years, while the incidence in the general population is only $0.038 \%$ (3). Furthermore, the associated risk factors of tobacco and alcohol that is associated with $85 \%$ of the non-FA HNSCC does not play as much of a role in FA; approximately $16 \%$ of FA HNSCC cases are associated with these risk factors (3). HNSCC is more aggressive in patients with FA, with early lymph node metastases and early soft tissue invasion, resulting in poorer prognoses than in HNSCC patients without FA (3). Secondary primary tumors occur in $63 \%$ of FA patients compared to only $15 \%$ in non-FA patients (3).

Furthermore, 2-year overall survival is only $49 \%$ in FA patients compared to $70 \%$ in non-FA patients (3). HNSCC most frequently presents in the oral cavity (65\%), compared to the larynx, hypopharynx and oropharynx, each at 10\%, which differs from the HNSCC in the general population. Due to significant toxic sequelae from use of radiation therapy and/ or chemotherapy in FA patients, surgical treatment is the main modality used. HNSCC in the general population is treated with radiation, chemotherapy and surgery. The highly metastatic potential of HNSCC in FA patients and inadequate treatment methods, leading to poor outcomes, create an urgent need to develop more effective, less toxic treatment alternatives.

Use of natural health products to prevent, inhibit and reverse carcinogenesis is gaining increasing importance, since scientific evidence shows that high consumption of fruits and vegetables are associated with reduced risk of various cancers $(4,5)$.

This study examines the effect of a mixture of phytobiologicals (PB), containing quercetin, curcumin, green tea, cruciferex, and resveratrol, on human FA HNSCC cell line OHSU-974 in vivo, in athymic nude mice bearing HNSCC xenografts, and in vitro, evaluating cell viability, MMP secretion, invasion and migration. 

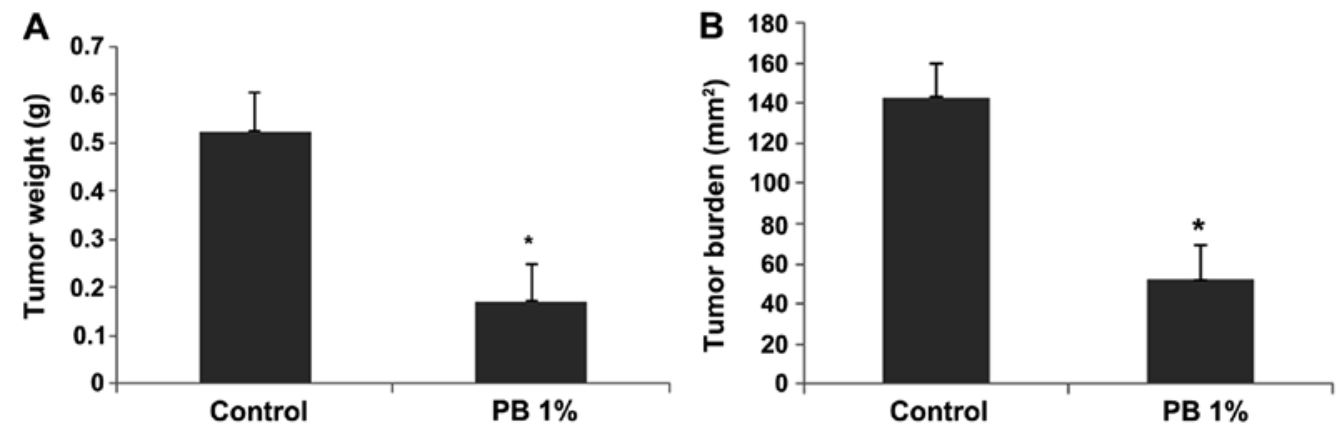

Figure 1. Effect of 1\% PB dietary supplementation on mean tumor weight of OHSU-974 xenografts in male nude mice injected with 3x10 ${ }^{6}$ OHSU-974 cells (A). Effect of 1\% PB dietary supplementation on tumor burden of OHSU-974 xenografts in male nude mice (B). "Indicates significance of $\mathrm{p}<0.0001$ with respect to control.

\section{Materials and methods}

Cancer cell line and culture. Human FAHNSCC cell line OHSU-974 was obtained from Fanconi Anemia Research Fund, Oregon Health and Science University (Portland, OR, USA). FAHNSCC cells were maintained in RPMI medium supplemented with $20 \%$ FBS, $100 \mathrm{U} / \mathrm{ml}$ penicillin and $100 \mu \mathrm{g} / \mathrm{ml}$ streptomycin. The media and sera used were obtained from ATCC, and antibiotics (penicillin and streptomycin) were from Gibco BRL, Long Island, NY.

Composition of the phytonutrient mixture. The mixture of nutrients (PB) was composed of the following in the ratio indicated: quercetin $400 \mathrm{mg}$; cruciferex $400 \mathrm{mg}$; curcumin $300 \mathrm{mg}$; resveratrol $50 \mathrm{mg}$; and standardized green tea extract [derived from green tea leaves, was obtained from US Pharma Lab Inc.; the certificate of analysis indicated the following characteristics: total polyphenol $80 \%$, catechins $60 \%$, epigallocatechin gallate (EGCG) 35\%, and caffeine $1.0 \%] 300 \mathrm{mg}$.

\section{In vivo studies}

Animals. Male athymic mice (NCr-nu/nu), approximately five weeks of age on arrival, were purchased from Simonsen Laboratories (Gilroy, CA, USA) and maintained in microisolator cages under pathogen-free conditions on a 12-h light/12-h dark schedule for a week. All procedures were performed according to humane and customary care and use of experimental animals and followed a protocol approved by the internal institutional animal safety review committee.

Experimental design. After housing for a week, the mice $(\mathrm{n}=12)$ were inoculated subcutaneously with $3 \times 10^{6}$ OHSU-974 cells in $0.2 \mathrm{ml} \mathrm{PBS}$ and $0.1 \mathrm{ml}$ Matrigel (BD Bioscience, Bedford, $\mathrm{MA})$. After injection, the mice were randomly divided into two groups; the control group of mice was fed regular Purina mouse chow and the PB group the regular diet supplemented with $1 \%$ PB (w/w). The regular diet was Laboratory Rodent Diet 5001 from Purina Mills (Gray Summit, MO, USA) LLC/Test Diet. The $1 \%$ PB diet was milled and pressed by Purina Mills, LLC and generated by Vitatech (Tustin, CA, USA). During the study, the mice consumed, on the average, $4 \mathrm{~g}$ of their respective diets per day. Thus, the supplemented mice received $\sim 40 \mathrm{mg}$ of PB per day. After four weeks, the mice were sacrificed and their tumors were excised and processed for histology.
Dimensions (length and width) of tumors were measured using a digital caliper, and the tumor burden was calculated using the following formula: $0.5 \mathrm{x}$ length $\mathrm{x}$ width. Mean weight of mice at initiation of study and termination of study did not differ significantly between the groups.

Histology. Tissue samples were fixed in $10 \%$ buffered formalin. All tissues were embedded in paraffin and cut at 4-5 microns. Sections were deparaffinized through xylene and graduated alcohol series to water and stained with hematoxylin and eosin (H\&E) for evaluation using a standard light microscope.

\section{In vitro studies}

Cell culture. Human HNSCC OHSU-974 cells were grown in RPMI, supplemented with $20 \%$ fetal bovine serum, penicillin $(100 \mathrm{U} / \mathrm{ml})$ and streptomycin $(100 \mathrm{mg} / \mathrm{ml})$ in 24-well tissue culture plates (Costar, Cambridge, MA, USA). Cells were incubated with $1 \mathrm{ml}$ of media at $37^{\circ} \mathrm{C}$ in a tissue culture incubator equilibrated with $95 \%$ air and $5 \% \mathrm{CO}_{2}$. At near confluence, the cells were treated with $\mathrm{PB}$, dissolved in media and tested at 0 , $10,25,50,75$ and $100 \mu \mathrm{g} / \mathrm{ml}$ in triplicate at each dose. Phorbol 12-myristate 13 -acetate (PMA), $100 \mathrm{ng} / \mathrm{ml}$ was added to cells to induce MMP-9 secretion. The plates were then returned to the incubator.

MTT assay. Cell viability was evaluated by MTT assay, a colorimetric assay based on the ability of viable cells to reduce a soluble yellow tetrazolium salt [3-(4,5-dimethylthiazol-2-yl) 2,5-diphenyl tetrazolium bromide] (MTT) to a blue formazan crystal by mitochondrial succinate dehydrogenase activity of viable cells. This test is a good index of mitochondrial activity and thus of cell viability. After $24 \mathrm{~h}$ of incubation, the cells were washed with phosphate buffered saline (PBS) and $500 \mu \mathrm{l}$ of MTT (Sigma \#M-2128) $0.5 \mathrm{mg} / \mathrm{ml}$ in media was added to each well. After MTT addition $(0.5 \mathrm{mg} / \mathrm{ml})$ the plates were covered and returned to the $37^{\circ} \mathrm{C}$ incubator for $2 \mathrm{~h}$, the optimal time for formazan product formation. Following incubation, the supernatant was carefully removed from the wells, the formazan product was dissolved in $1 \mathrm{ml}$ DMSO, and absorbance was measured at $570 \mathrm{~nm}$ in Bio Spec 1601, Shimadzu spectrometer. The $\mathrm{OD}_{570}$ of the DMSO solution in each well was considered to be proportional to the number of cells. The $\mathrm{OD}_{570}$ of the control (treatment without supplement) was considered $100 \%$. 


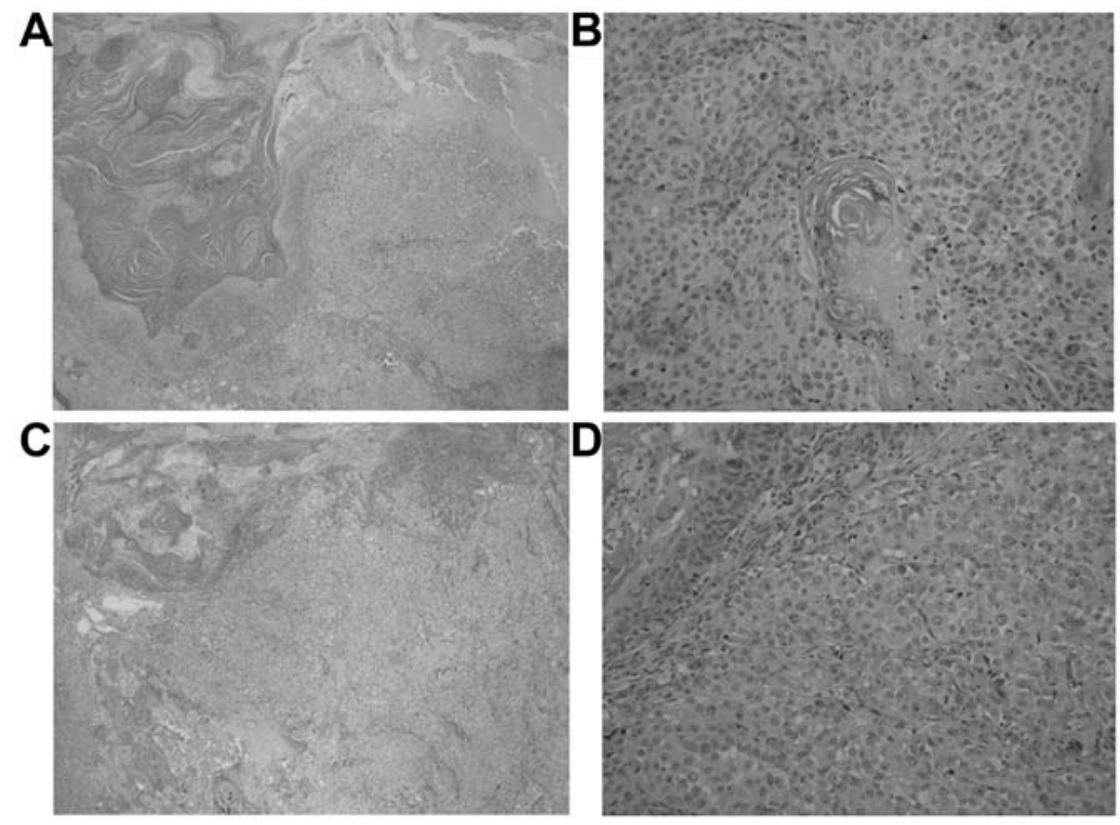

Figure 2. Histopathology of tumors. Representative tumors from control (A) control, x40 magnification; (B) control, x200 magnification and 1\% PB-supplemented mice; (C) $1 \%$ PB, x40 magnification; (D) $1 \%$ PB, x200 magnification.

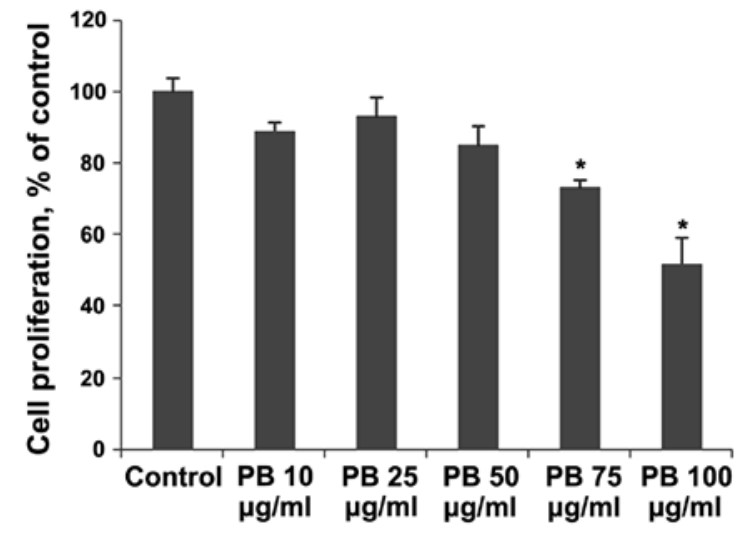

Figure 3. Effect of PB on viability of OHSU-974 cells: MTT 24 h. "Indicates significance of at least $\mathrm{p}=0.0004$ with respect to control.

Gelatinase zymography. Gelatinase zymography was performed in $10 \%$ Novex Pre-Cast SDS Polyacrylamide Gel (Invitrogen Corp.) in the presence of $0.1 \%$ gelatin under nonreducing conditions. Culture media $(20 \mu \mathrm{l})$ were mixed with sample buffer and loaded for SDS-PAGE with Tris glycine SDS buffer, as suggested by the manufacturer (Novex). Samples were not boiled before electrophoresis. Following electrophoresis the gels were washed twice in 2.5\% Triton X-100 for $30 \mathrm{~min}$ at room temperature to remove SDS. The gels were then incubated at $37^{\circ} \mathrm{C}$ overnight in substrate buffer containing $50 \mathrm{mM}$ Tris- $\mathrm{HCl}$ and $10 \mathrm{mM} \mathrm{CaCl}_{2}$ at $\mathrm{pH} 8.0$ and stained with $0.5 \%$ Coomassie Blue R250 in 50\% methanol and 10\% glacial acetic acid for $30 \mathrm{~min}$ and destained. Upon renaturation of the enzyme, the gelatinases digested the gelatin, producing clear bands against an intensely stained background. Protein standards were run concurrently and approximate molecular weights were determined by plotting the relative mobilities of known proteins.
Matrigel invasion. Invasion studies were conducted using Matrigel (Becton Dickinson) inserts in 24-well plates. Suspended in medium, OHSU-974 cells were supplemented with nutrients, as specified in the design of the experiment and seeded on the insert in the well. Thus, both the medium on the insert and in the well contained the same supplements. The plates with the inserts were then incubated in a culture incubator equilibrated with $95 \%$ air and $5 \% \mathrm{CO}_{2}$ for $24 \mathrm{~h}$. After incubation, the media from the wells were withdrawn. The cells on the upper surface of the inserts were gently scrubbed away with cotton swabs. The cells that had penetrated the Matrigel membrane and migrated onto the lower surface of the Matrigel were stained with H\&E and visually counted under the microscope.

Cell migration: scratch test. To study cell migration, a 2-mm wide single uninterrupted scratch was made from the top to bottom of culture plates of OHSU-947 cells grown to confluence. Culture plates were washed with PBS and incubated with $\mathrm{PB}$ in medium and tested at $0,10,25,50$ and $100 \mu \mathrm{g} / \mathrm{ml}$, in triplicate at each dose for $24 \mathrm{~h}$. Cells were washed with PBS, fixed and stained with H\&E and photomicrographs were taken.

Morphology. Morphology of cells cultured for $24 \mathrm{~h}$ in test concentrations of $\mathrm{PB}$ was evaluated by hematoxylin and eosin (H\&E) staining and observed and photographed by microscopy.

Statistical analysis. The results are expressed as means $\pm \mathrm{SD}$, as indicated in the results, for the groups. Data were analyzed by independent sample ' $t$ ' test.

\section{Results}

In vivo

Tumor growth and burden. NM strongly inhibited the growth of OHSU-974 xenografts in nude mice. Mean tumor weight 


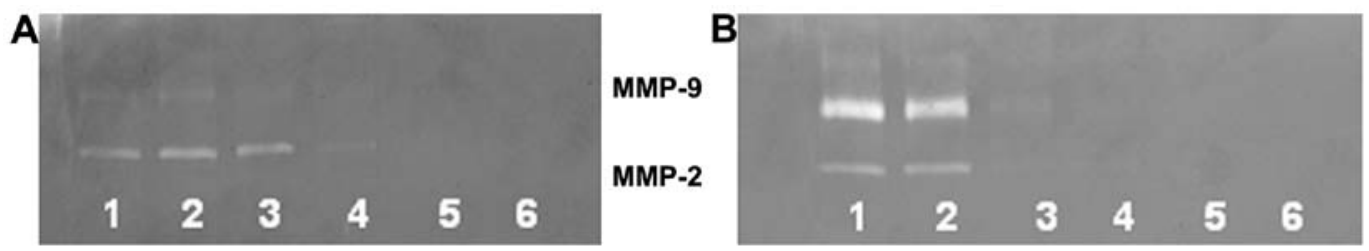

Figure 4. Effect of PB on untreated (A) OHSU-974 cell MMP-2 and MMP-9 secretion and on PMA (100 ng/ml)-treated (B) OHSU-974 cell MMP-2 and MMP-9 secretion. Lane 1, control; lanes 2-6, PB 10, 25, 50, 75, $100 \mu \mathrm{g} / \mathrm{ml}$.

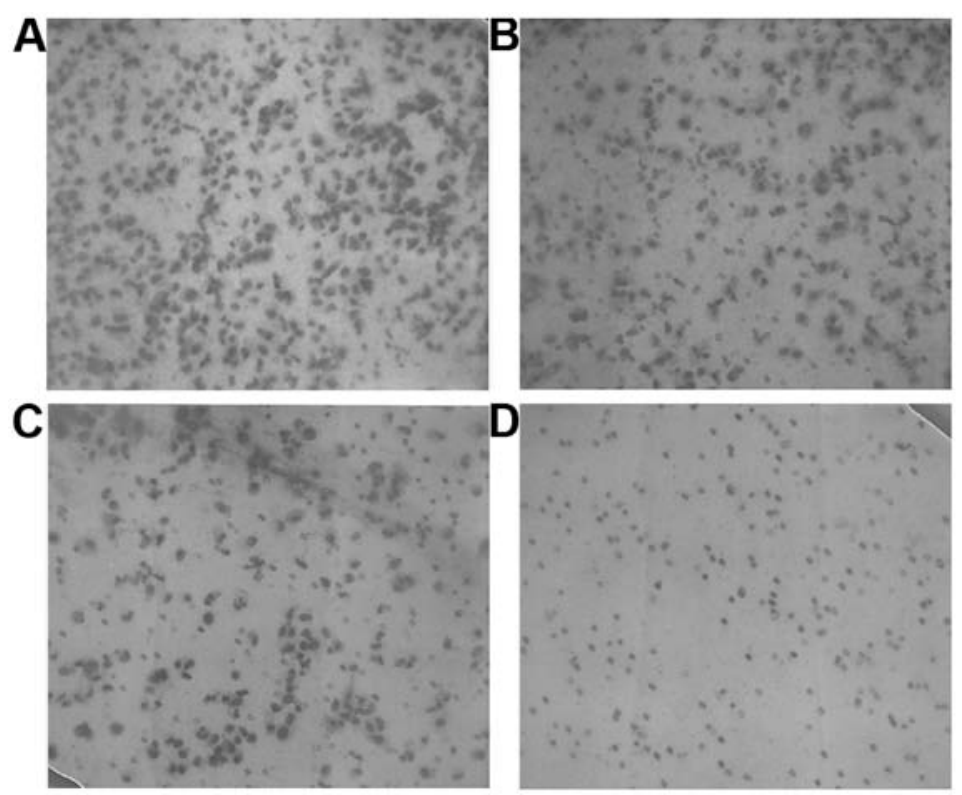

Figure 5. Effect of PB on Matrigel invasion of OHSU-974 cells : photomicrographs. (A) Control; (B) PB, $10 \mu \mathrm{g} / \mathrm{ml}$; (C) PB, $25 \mu \mathrm{g} / \mathrm{ml}$; (D) PB, $50 \mu \mathrm{g} / \mathrm{ml}$.

was inhibited by $67.6 \%(\mathrm{p}<0.0001)$ with PB $1 \%$ dietary supplementation, as shown in Fig. 1A, and tumor burden was inhibited by $63.6 \%(\mathrm{p}<0.0001)$, as shown in Fig. 1B.

Histology. The tumors from both groups were irregularly round, ulcerated, skin subcutaneous masses, consistent with squamous cell carcinoma. Tumors from control and PB-supplemented mice were similar morphologically, but the tumors from supplemented mice were significantly smaller in size (Fig. 2).

In vitro. Cytotoxicity. $\mathrm{PB}$ exhibited dose-dependent toxicity to HNSCC OHSU-974 cells in vitro with $27 \%(\mathrm{p}=0.0003)$ at $75 \mu \mathrm{g} / \mathrm{ml}$ and $48 \%$ ( $\mathrm{p}=0.0004)$ at $100 \mu \mathrm{g} / \mathrm{ml}$, compared to the control, as shown in Fig. 3.

Gelatinase zymography. Zymography demonstrated MMP-2 and MMP-9 secretion by normal and enhanced MMP-9 with PMA-treated OHSU-947 cells. PB inhibited secretion of both MMPs in a dose-dependent fashion with virtual total inhibition of MMP-9 and MMP-2 at $50 \mu \mathrm{g} / \mathrm{ml}$, as shown in Fig. 4A and B.

Matrigel invasion. PB significantly inhibited OHSU-974 cell invasion through Matrigel in a dose-dependent manner, with total block at $50 \mu \mathrm{g} / \mathrm{ml}$, as shown in Fig. 5
Cell migration: scratch test. PB reduced cell migration in a dose-dependent manner, with complete block of OHSU-974 cells at $50 \mu \mathrm{g} / \mathrm{ml}$. Photomicrographs of the results for the scratch tests for OHSU-974 cells are shown in Fig. 6.

Morphology. H\&E staining showed no morphological changes below PB $50 \mu \mathrm{g} / \mathrm{ml}$, as shown in Fig. 7.

\section{Discussion}

The results of the in vivo study of human HNSCC xenografts in immune impaired (athymic) nude mice demonstrated significant suppression of HNSCC OHSU-974 tumor growth (67.6\% inhibition of mean tumor weight and 63.6\% inhibition of mean tumor burden with PB $1 \%$ dietary supplementation). Results from the cellular proliferation study support the in vivo findings, as $\mathrm{PB}$ showed increased toxicity in OHSU974 cells in a dose-dependent manner, with $48 \%$ inhibition of cell growth in cells exposed to $100 \mu \mathrm{g} / \mathrm{ml} \mathrm{PB}$.

Invasion of host tissues is dependent on tumor cell adhesion, cell migration, and proteolytic degradation of the ECM by MMPs (6). MMPs, especially MMP-2 and MMP-9 are prognostic for survival and metastatic potential in head and neck squamous carcinomas. Kawamata et al (7) observed increased activity of pro-MMP-9 and active MMP-2 in cancer cell nests in human oral squamous cell carcinoma compared 

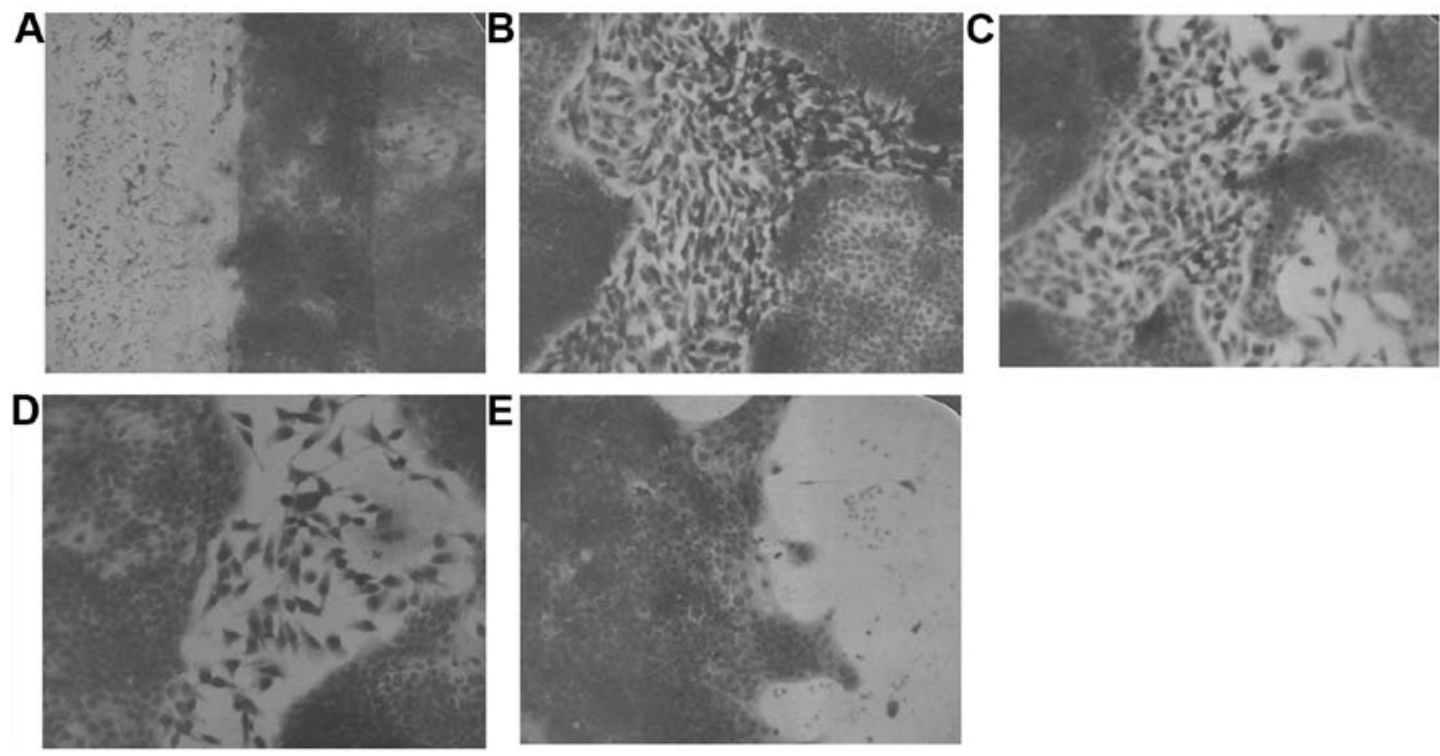

Figure 6. Effect of PB on migration: scratch test. (A) Control, $0 \mathrm{~h}$; (B) control, $24 \mathrm{~h}$; (C) PB, $10 \mu \mathrm{g} / \mathrm{ml} 24 \mathrm{~h}$; (D) PB, $25 \mu \mathrm{g} / \mathrm{ml} 24 \mathrm{~h}$; (E) PB, $50 \mu \mathrm{g} / \mathrm{ml} 24 \mathrm{~h}$.
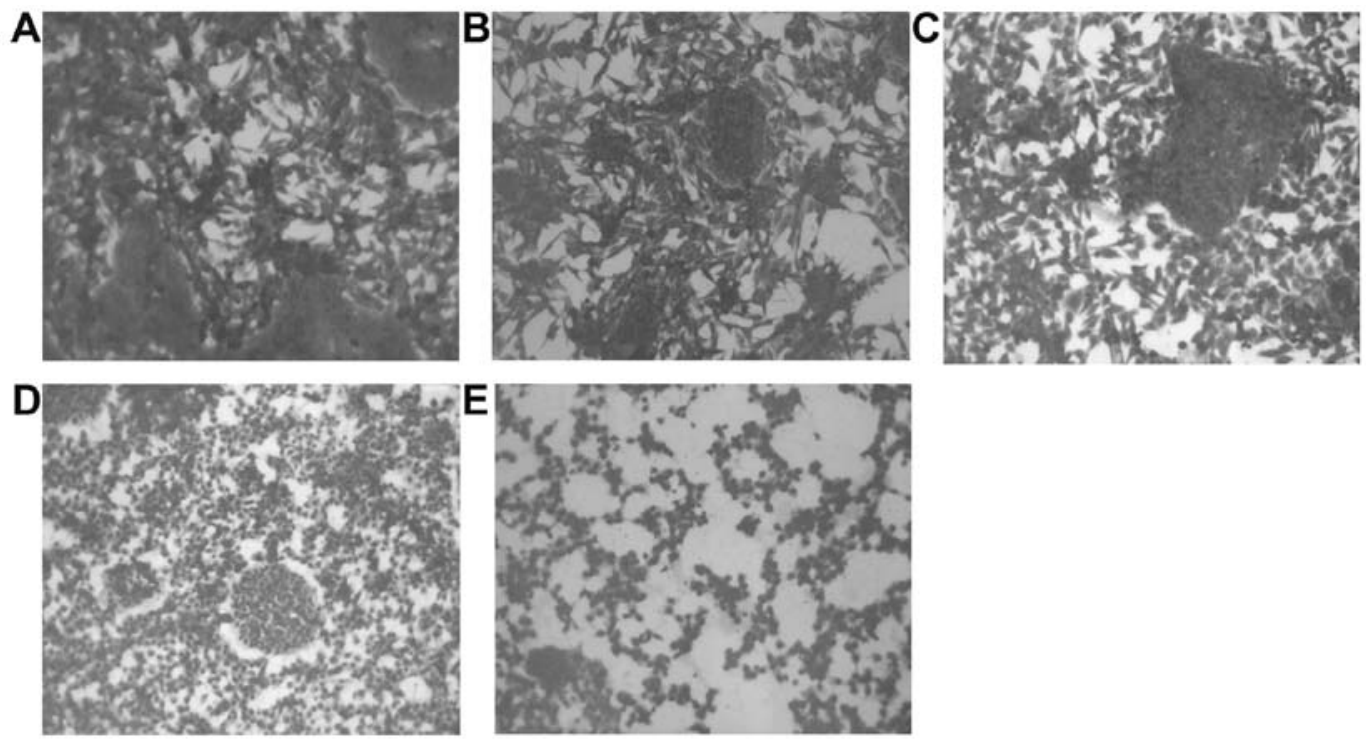

Figure 7. Effect of PB on morphology of OHSU-974 cells: H\&E. (A) Control; (B) PB, $10 \mu \mathrm{g} / \mathrm{ml}$; (C) PB, $25 \mu \mathrm{g} / \mathrm{ml}$; (D) PB, $50 \mu \mathrm{g} / \mathrm{ml}$; (E) PB, $100 \mu \mathrm{g} / \mathrm{ml}$.

with normal surrounding gingival tissue and significantly higher MMP-2 activity in metastatic cancer cell nests. Patel et al (8) reported significant elevation of latent, active and total forms of MMP-2 and MMP-9 in malignant tissue compared with adjacent normal tissues in oral cancer patients. In addition, MMP-2 was correlated with lymph node metastatic development (8).

In examining a group of patients with early stage oral squamous cell carcinoma, Katayama et al (9) found that patients who developed regional lymph node and/or distant metastasis showed significantly increased MMP-9 and TIMP-2 expression than patients without any tumor metastasis; expression of MMP-9 and TIMP-2 correlated with the worst cause-specific survival. Reidel et al (10) found that MMP-9 expression in patients with HNSCC correlated with poor survival of patients, as well as high VEGF expression and higher mean vessel density than MMP-9-negative tumors, suggesting MMP-9 functions as a regulator of tumor angiogenesis supporting endothelial cell invasion in human head and neck cancer. Kuhara et al (11) demonstrated a significant decrease in ECM staining (indicating loss of ECM) in invasive and metastatic cases of oral squamous cell carcinoma with increased expression of MMP-1, MMP-2 and MMP-9.

The results from our in vitro study of HNSCC OSH-947 cells demonstrated potent, significant suppression of invasive parameters by the phytonutrient mixture. PB inhibited MMP-2 and MMP-9 secretion with total block at $50 \mu \mathrm{g} / \mathrm{ml}$ and $100 \%$ inhibition of invasion of cells through Matrigel at $50 \mu \mathrm{g} / \mathrm{ml}$. Migration of cells using scratch test showed total block at PB $50 \mu \mathrm{g} / \mathrm{ml}$.

Use of natural health products to prevent, inhibit and reverse carcinogenesis is gaining increasing importance, 
since scientific evidence shows that high consumption of fruits and vegetables are associated with reduced risk of various cancers $(4,5)$. PB was formulated by defining critical physiological targets in cancer progression and metastasis. Curcumin (a derivative of turmeric), used for centuries to treat inflammatory conditions, has been reported to affect multiple targets in many cancers: leukemia, lymphoma, gastrointestinal cancers, genitourinary cancers, breast cancer, ovarian cancer, head and neck squamous cell carcinoma, lung cancer, melanoma, neurological cancers and sarcomas (12). Curcumin has been reported to down regulate cancer cell proliferation, invasion (MMP-9 and adhesion molecules), angiogenesis (VEGF) and metastasis and to induce apoptosis (12). Anticarcinogenic properties of cruciferex (derived from cabbage, cauliflower, carrot and broccoli) include detoxification and excretion of carcinogens, protection against oxidative stress, inhibition of cancer cell proliferation and increase in apoptosis resulting in inhibition of tumor growth (13). Green tea extract has been shown to modulate cancer cell growth, metastasis, angiogenesis, and other aspects of cancer progression (14-19).

Resveratrol has been shown to inhibit cellular events associated with tumor initiation, promotion and progression, partially attributable to its antioxidant activities and inhibition of Cox-2 and inhibition of protein kinase C, a key mediator of tumor promotion stage of carcinogenesis (20). Among its anticarcinogenic effects, resveratrol inhibits cell proliferation and induces apoptosis (20). Bishayee et al reported that resveratrol affects carcinogenesis by modulating signal transduction pathways that control cell division and growth, apoptosis, inflammation, angiogenesis and metastasis (21). Cancer preventive effects of quercetin include induction of cell cycle arrest, apoptosis and antioxidant functions (22). Induction of apoptosis by quercetin in cancer cells during different cell cycle stages without affecting normal cells has been documented in various cancers in vivo and in vitro (22).

In conclusion, current treatment methods for Fanconi anemia-associated cancers are generally ineffective and especially toxic to these patients. Thus, there is a need for development of effective therapeutic agents for these cancers with minimal toxicity. Our studies demonstrated that the mixture of the non-toxic components of PB significantly inhibited the growth and tumor burden of FA HNSCC cell line OHSU-974 in vivo. In addition, invasive parameters, such as OHSU-974 cell line MMP-2 and -9 secretion and invasion were significantly inhibited by $\mathrm{PB}$ in vitro. These findings suggest potential of PB in treatment of FA HNSCC.

\section{Acknowledgements}

This study was funded by Dr Rath Health Foundation (Santa Clara, CA, USA), a non-profit organization. Consulting pathologist Alexander de Paoli, DVM, PhD, IDEXX Reference Laboratories provided histopathology slides of HNSCC OHSU-974 tumors.

\section{References}

1. Alter BP, Greene MH, Velazquez I and Rosenberg PS: Cancer in Fanconi anemia. Blood 101: 2072-2073, 2003.
2. Kutler DI, Auerbach AD, Satagopan J, Giampietro PF, Batish SD, Huvos AG, Goberdhan A, Shah JP and Singh B: High incidence of head and neck squamous cell carcinoma in patients with Fanconi anemia. Arch Otolaryngol Head Neck Surg 129: 106-112, 2003.

3. Singh B: Head and neck squamous carcinoma in Fanconi anemia patients. In: Fanconi Anemia: Guidelines for Diagnosis and Management. Eiler ME, Fohnmayer D, Forhnmayer L, Larsen K and Owen J (eds). 3rd edition. Fanconi Anemia Research Fund, Inc., 2008.

4. Adlercreutz H: Western diet and Western diseases: Some hormonal and biochemical mechanisms and associations. Scand J Clin Lab Invest (Suppl) 201: 3-23, 1990.

5. Miller AB: Diet and cancer. A review. Acta Oncol 29: 87-95, 1990.

6. Duffy MJ: The role of proteolytic enzymes in cancer invasion and metastasis. Clin Exp Metastasis 10: 145-155, 1992.

7. Kawamata H, Uchida D, Hamano H, Kimura-Yanagawa T, Nakashiro KI, Hino S, Omotehara F, Yoshida $\mathrm{H}$ and Sato $\mathrm{M}$ : Active-MMP2 in cancer cell nests of oral cancer patients: Correlation with lymph node metastasis. Int J Oncol 13: 699-704, 1998.

8. Patel BP, Shah SV, Shukla SN, Shah PM and Patel PS: Clinical significance of MMP-2 and MMP-9 in patients with oral cancer. Head Neck 29: 564-572, 2007.

9. Katayama A, Bandoh N, Kishibe K, Takahara M, Ogino T, Nonaka S and Harabuchi Y: Expressions of matrix metalloproteinases in early-stage oral squamous cell carcinoma as predictive indicators for tumor metastases and prognosis. Clin Cancer Res 10: 634-640, 2004

10. Riedel F, Götte K, Schwalb J, Bergler W and Hörmann K: Expression of 92-kDa type IV collagenase correlates with angiogenic markers and poor survival in head and neck squamous cell carcinoma. Int J Oncol 17: 1099-1105, 2000.

11. Kurahara S, Shinohara M, Ikebe T, Nakamura S, Beppu M, Hiraki A, Takeuchi $\mathrm{H}$ and Shirasuna K: Expression of MMPS, MT-MMP, and TIMPs in squamous cell carcinoma of the oral cavity: Correlations with tumor invasion and metastasis. Head Neck 21: 627-638, 1999.

12. Anand P, Sundaram C, Jhurani S, Kunnumakkara AB and Aggarwal BB: Curcumin and cancer: An 'old-age' disease with an 'age-old' solution. Cancer Lett 267: 133-164, 2008.

13. Keck AS and Finley JW: Cruciferous vegetables: Cancer protective mechanisms of glucosinolate hydrolysis products and selenium. Integr Cancer Ther 3: 5-12, 2004

14. Valcic S, Timmermann BN, Alberts DS, Wächter GA, Krutzsch M, Wymer J and Guillén JM: Inhibitory effect of six green tea catechins and caffeine on the growth of four selected human tumor cell lines. Anticancer Drugs 7: 461-468, 1996.

15. Mukhtar H and Ahmad N: Tea polyphenols: Prevention of cancer and optimizing health. Am J Clin Nutr 71 (Suppl 6): S1698-S1702, discussion S1703-S1704, 2000.

16. Yang GY, Liao J, Kim K, Yurkow EJ and Yang CS: Inhibition of growth and induction of apoptosis in human cancer cell lines by tea polyphenols. Carcinogenesis 19: 611-616, 1998.

17. Taniguchi S, Fujiki H, Kobayashi H, Go H, Miyado K, Sadano H and Shimokawa R: Effect of (-)-epigallocatechin gallate, the main constituent of green tea, on lung metastasis with mouse B16 melanoma cell lines. Cancer Lett 65: 51-54, 1992.

18. Hara Y: Green tea: Health Benefits and Applications. Marcel Dekker, Inc., New York, Basel, 2001.

19. Harakeh S, Abu-El-Ardat K, Diab-Assaf M, Niedzwiecki A, El-Sabban M and Rath M: Epigallocatechin-3-gallate induces apoptosis and cell cycle arrest in HTLV-1-positive and -negative leukemia cells. Med Oncol 25: 30-39, 2008.

20. Cal C, Garban H, Jazirehi A, Yeh C, Mizutani Y and Bonavida B: Resveratrol and cancer: Chemoprevention, apoptosis, and chemoimmunosensitizing activities. Curr Med Chem Anticancer Agents 3: 77-93, 2003.

21. Bishayee A: Cancer prevention and treatment with resveratrol: From rodent studies to clinical trials. Cancer Prev Res (Phila) 2: 409-418, 2009.

22. Gibellini L, Pinti M, Nasi M, Montagna JP, De Biasi S, Roat E, Bertoncelli L, Cooper EL and Cossarizza A: Quercetin and cancer chemoprevention. Evid Based Complement Alternat Med 2011: 591356, 2011. 